\title{
Hepatotoxicidade induzida por sulfassalazina: relato de caso
}

\author{
Hepatotoxicity induced by sulfasalazine: case report
}

\author{
RODRIGO ROCHA BATISTA ${ }^{1}$, BÁRBARA HELOISA ZANCHETTA POZZOBON ${ }^{1}$, IDBLAN CARVALHO DE \\ ALBUQUERQUE², GALDINO JOSÉ SITONIO FORMIGA ${ }^{3}$
}

\begin{abstract}
${ }^{1}$ Médico Residente de Coloproctologia do Hospital Heliópolis - São Paulo (SP), Brasil. ${ }^{2}$ Médico Assistente do Serviço de Coloproctologia do Hospital Heliópolis - São Paulo (SP), Brasil. ${ }^{3}$ Chefe do Serviço de Coloproctologia do Hospital Heliópolis - São Paulo (SP), Brasil.
\end{abstract}

BATISTA RR, POZZOBON BHZ, ALBUQUERQUE ICD, FORMIGA GJS. Hepatotoxicidade induzida por sulfassalazina: relato de caso. Rev bras Coloproct, 2011;31(2): 210-212.

RESUMO: A sulfassalazina é ainda muito utilizada nas doenças inflamatórias intestinais, sobretudo na retocolite ulcerativa leve e moderada. Entretanto, seu uso é relacionado a vários efeitos colaterais, incluindo disfunção hepática grave.Este é um relato do caso de paciente masculino, 21 anos, portador de retocolite ulcerativa moderada, com queixa de inapetência, febre, artralgia e icterícia, há sete dias. Antecedente pessoal de uso de sulfassalazina $4 \mathrm{~g}$ /dia há seis semanas. Ao exame físico apresentava-se ictérico, com exantema em membros e edema de membros inferiores. Exames complementares mostravam aumento de bilirrubinas, enzimas hepáticas e canaliculares e da proteína $\mathrm{C}$ reativa. Com o diagnóstico de hepatotoxicidade por sulfassalazina, foi suspensa a medicação e introduzido prednisona $20 \mathrm{mg} /$ dia e ciprofloxacino $1 \mathrm{~g} /$ dia. Recebeu alta no terceiro dia de internação após melhora clínica e laboratorial. Atualmente encontra-se assintomático e em uso de azatioprina $150 \mathrm{mg} / \mathrm{dia}$.

Palavras-chave: hepatite; idiossincrasia; proctocolite; sulfassalazina; terapêutica.

\section{INTRODUÇÃO}

Em 1941, Svartz utilizou pela primeira vez a sulfassalazina (SSZ) no tratamento da retocolite ulcerativa $(\mathrm{RCU})^{1}$. Baron et al., em 1962, realizaram o primeiro ensaio clínico sobre o uso da SSZ na RCU, com significantes resultados ${ }^{2}$ Desde então, diversos estudos comprovaram sua eficácia nas doenças inflamatórias intestinais, inclusive na doença de Crohn.

Entretanto, a SSZ está relacionada a vários efeitos colaterais, incluindo disfunção hepática grave $^{3-6}$. O presente relato de caso descreve uma reação de hipersensibilidade sistêmica associada à hepatotoxicidade por SSZ.

\section{RELATO DO CASO}

E.M., masculino, 21 anos, com diagnóstico de RCU moderada, foi admitido no serviço de emergência com queixa de inapetência, febre, artralgia e icterícia há sete dias. Antecedente pessoal de uso de SSZ 4g/dia há seis semanas. Ao exame físico, apresentava-se afebril, ictérico $(2+/ 4+)$, com máculas eritematosas em membros e edema de membros inferiores $(2+/ 4+)$.

Exames complementares na admissão mostravam aumento de bilirrubinas, enzimas hepáticas e canaliculares e da proteína $\mathrm{C}$ reativa (PCR). Com o diagnóstico de hepatotoxicidade por SSZ, foi suspensa a medicação e introduzido prednisona 20 $\mathrm{mg} /$ dia e ciprofloxacino $1 \mathrm{~g} / \mathrm{dia}$.

Trabalho realizado no Serviço de Coloproctologia do Hospital Heliópolis - São Paulo (SP), Brasil.

Fonte de financiamento: não há

Conflito de interesse: nada a declarar

Recebido em: 26/08/2009

Aprovado em: 24/09/2009 
Recebeu alta no terceiro dia de internação, após melhora dos sintomas e queda dos níveis de bilirrubinas e enzimas hepáticas (gráficos 1 e 2). No sexto mês de seguimento ambulatorial, após a disfunção hepática, está assintomático e em uso de azatioprina $150 \mathrm{mg} /$ dia.

\section{DISCUSSÃO}

A SSZ é o fármaco de escolha no tratamento da RCU leve e moderada ${ }^{7}$. É composta pela união do ácido 5-aminossalicílico e do radical sulfapiridina, através de uma ligação diazo, exercendo ação antiinflamatória no cólon, após a liberação do núcleo

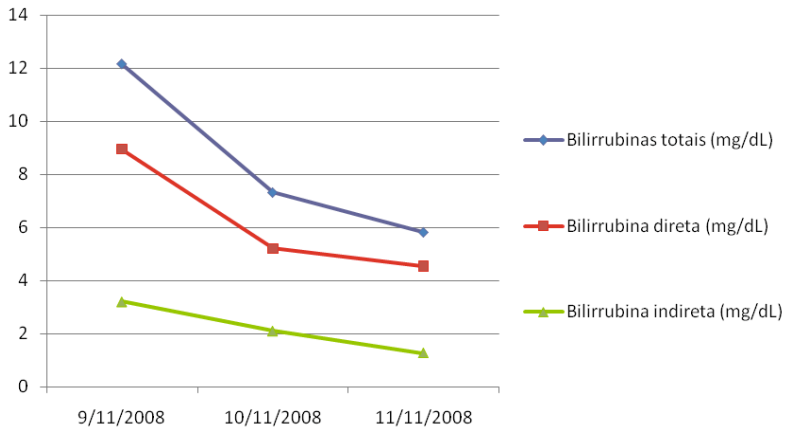

Gráfico 1. Niveis séricos de bilirrubinas totais e frações.

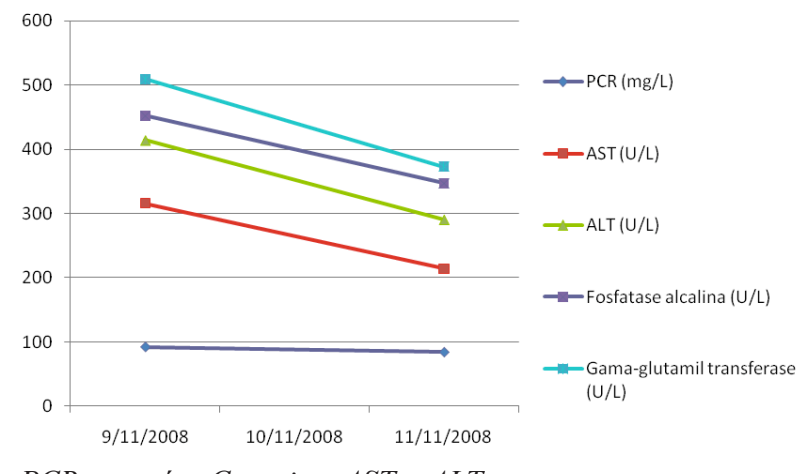

PCR: proteína C reativa; AST: ; ALT: .

Gráfico 2. Niveis séricos de proteina C reativa, aminotransferases e enzimas canaliculares. ácido pelas bactérias produtoras de azorredutase. A sulfapiridina é absorvida pelo cólon, acetilada e conjugada pelo fígado e, finalmente, excretada pela urina ${ }^{4,8}$.

Reações adversas são frequentes e aparecem em 5-55\% dos pacientes com doença inflamatória intestinal $^{4}$. Elas incluem efeitos dose-dependentes, tais como dispepsia, náuseas, vômitos, cefaleia, oligoespermia reversível e reações idiossincráticas, tais como descamação cutânea, febre, discrasias sanguíneas, nefrite intersticial, neutropenia, pneumonite, pancreatite, neurotoxicidade e hepatotoxicidade ${ }^{3-6}$. Esses efeitos colaterais são mais frequentes em pacientes recebendo SSZ na dose de quatro gramas ou mais diariamente ${ }^{4,8}$.

Das et al. relataram elevada incidência de reações idiossincráticas atribuídas a SSZ nos pacientes com fenótipo de acetiladores lentos que, consequentemente, mantêm níveis séricos elevados da droga ${ }^{4}$. Hautekeete et al. mostraram que $70-90 \%$ dos pacientes intolerantes a SSZ foram tolerantes a mesalazina ou olsalazina (formas isoladas do ácido 5-aminossalicílico), enquanto o restante apresentaram efeitos adversos semelhantes aos da SSZ. Assim, concluíram que, tanto o radical sulfapiridina, quanto o ácido 5-aminossalicílico, podem ser responsáveis pelos efeitos adversos 5 .

As manifestações clínicas da hepatotoxicidade pela SSZ incluem febre, icterícia, exantema, linfadenopatia, eosinofilia, leucocitose com eosinofilia, elevação dos níveis de enzimas hepáticas e canaliculares, bilirrubinas e da proteína $\mathrm{C}$ reativa ${ }^{2-5,8}$. Nosso paciente apresentou sinais e sintomas semelhantes ao descrito, exceto os achados de linfadenopatia e eosinofilia.

A hepatotoxicidade devido a SSZ é rara, com início dos sintomas entre o $11^{\circ}$ e $21^{\circ}$ dias após a sua introdução ${ }^{8}$. Nosso paciente apresentou início dos sintomas apenas cinco semanas depois do início do tratamento, com boa evolução clínica após suspensão da droga, ressaltando a importância do acompanhamento clínico e laboratorial rigoroso nos primeiros meses de administração da SSZ. 
ABSTRACT: The sulfasalazine is widely used in inflammatory bowel disease, especially in mild and moderate ulcerative rectocolitis. However, its use is related to several side effects, including severe liver dysfunction. We report the case of male patient, 21 years, with the moderate ulcerative rectocolitis, complaining of inappetence, fever, arthralgia and jaundice for seven days. Personal history includes use of sulfasalazine $4 \mathrm{~g}$ /day during six weeks. The physical examination revealed jaundiced, with members in rash and lower extremity edema. Laboratory exams showed an increase in bilirubin, liver enzymes and canalicular and C-reactive protein. With the diagnosis of hepatotoxicity by sulfasalazine, this medication was suspended, and introduced prednisone $20 \mathrm{mg} / \mathrm{day}$ and ciprofloxacin 1g/day. He was discharged on the third day of admission after clinical and laboratorial improvement. Currently, he is asymptomatic and in use of azathioprine $150 \mathrm{mg} / \mathrm{day}$.

Keywords: hepatitis; idiosyncrasy; proctocolitis; sulfasalazine; therapeutics.

\section{REFERÊNCIAS}

1. Svartz N. Ett nytt sulfonamidpreparat. Nord, med 1941;9:554.

2. Baron JH, Connel AM, Lennard-Jones JE, Avery-Jones F. Sulphasalazine and salicylazosulphadimidine in ulcerative colitis. Lancet 1962;1(7239):1094-6.

3. Hayllar J, Bjarnason I. Sulphasalazine in ulcerative colitis: in memorian? Gut 1992;32(5):462-3.

4. Das KM, Eastwood MA, McManus JPA, Sircus W. Adverse reactions during salicylazosulfapyridine therapy and the relation with drug metabolism and the acetylator phenotype. N Eng J Med 1973;289(10):491-5.

5. Hautekeete ML, Bourgeois N, Potvin P, Duville L, Reynaert $H$, Devis G, et al. Hypersensitivity with hepatotoxicity to mesalazine after hypersensitivity to sulfasalazine. Gastroenterology 1992;103(6):1925-7.
6. Ransford RAJ, Langman MJS. Sulphasalazine and mesalazine: serious adverse reactions re-evaluated on the basis of suspected adverse reaction reports to the Committee on Safety of Medicines. Gut 2002;51(4):536-9.

7. Travis SPL, Stange EF, Lémann M, Oresland T, Bemelman WA, Chowers Y, et al. European evidence-based consensus on the management of ulcerative colitis: current management. J Crohns Colitis 2008;2(1):24-62.

8. Fich A, Schwartz J, Braverman D, Zifroni A, Rachmilewitz D. Sulfasalazine hepatotoxicity. Am J Gastroenterol 1984;79(5):401-2.

\section{Endereço para Correspondência:}

Galdino José Sitonio Formiga

Rua Cônego Xavier, 276, Vila Heliópolis

CEP: 04231-030 - São Paulo (SP), Brasil

E-mail: gformiga@ig.com.br 